\title{
INTRA-TECHAL BACLOFEN PUMP TREATMENT OF SPASTICITY: UNDERUSED DESPITE COST-EFFECTIVENESS
}

\section{Nuri Attagour}

West Midlands Rehabilitation Centre, Birmingham , UK

Introduction: Intrathecal Baclofen (ITB) treatment in the UK is judged based on a criteria outlined in the Clinical Commissioning Policy:ITB treatment document issued on April 2013.1 The criteria include patient who has chronic, severe, diffuse spasticity and/or dystonia of spinal or cerebral origin which renders them a full time wheelchair user or bed bound. The main purpose of the policy is to ensure equal access to health services and health outcomes achieved in line with the Health and social Care Act 2010. However, a recent review of the NHS England records between 2009 to 2014 in order to evaluate the improvement in provision of ITB services demonstrated that ITB provision has not changed over that period.2

\section{Conclusion and Discussions:}

The main reasons for no improvement in the ITB service provision were attributed to:

- Poor service coordination and management between different specialities including rehabilitation, neurosurgery and/or neurologists.

- Continuing inadequate resources and funding of healthcare particularly rehabilitation services.

- Increasing demand on rehabilitation services to respond to requirements of the acute services.

- There is a skepticism in a new technology involving a permanent implantation due to fear of harm and the concern of plentiful complications despite high level evidence of its cost effectiveness.

- There is increase in challenge of setting up new services and its scrutiny due to the current global economic down turn.

- Reduced awareness of the non rehabilitation healthcare professionals of the effectiveness of ITB.

- Increased cost of the service level agreements of neurosurgical services with district general hospitals to provide priority services of acute emergency life saving procedures.

- Also the very strict criteria used by commissioners to justify funding for referral to ITB service for implantation and follow up refilling.

\section{References:}

1. NHS commissioning Board Clinical Reference Group for Neurosciences.Clinical Commissioning Policy:Intratechal Baclofen (ITB), April 2013. Available online only at: https://www.england.nhs.uk/wp-content/ uploads/2013/04/d04-p-c.pdf

2. Narendran RC, Duarte RV, Valyi A, Eldabe S. The need for and provision of intrathecal baclofen therapy for the management of spasticity in England: an assessment of the Hospital Episode Statistics database. BMJ Open. 2015; 5(6) 


\section{Summary of Spasticity Management}
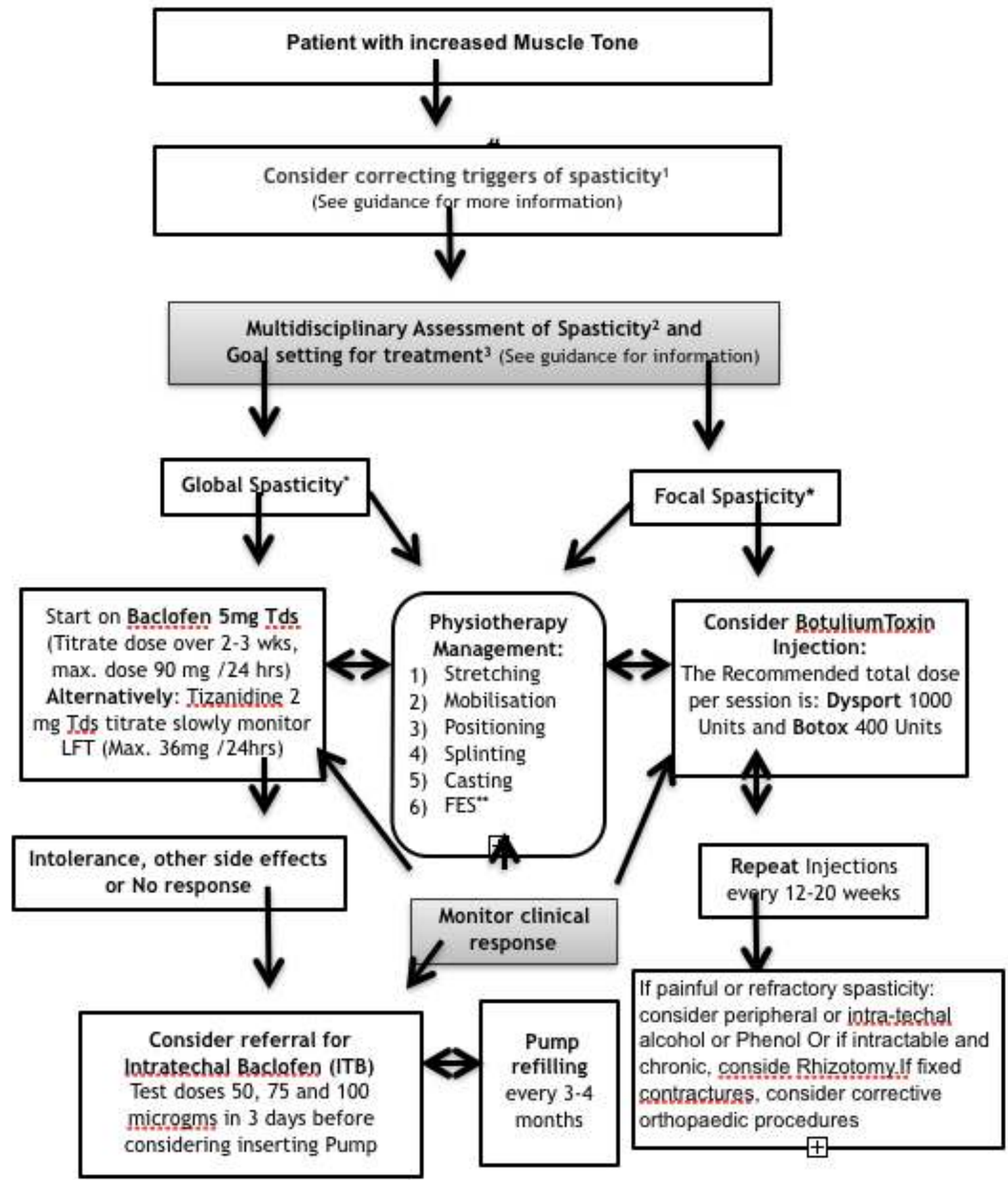

* Focal Spasticity: when one joint muscle group is affected, while global when more than one joint muscle groups. ${ }^{* *}$ FES: Functional Electrical Stimulation 